\title{
DIE METING VAN DIE INVLOED VAN ORGANISASIEGROOTTE OP BRUIN WERKERS SE HOUDINGS EN GEDRAG *
}

\author{
R. VAN DER BANK
}

DEPARTEMENT SIELKUNDE

UNIVERSITEIT VAN WES-KAAPLAND

\begin{abstract}
A survey of the literature indicates inconsistencies regarding the influence of size of organizations on variables such as efficiency of personnel selection systems, training, labour turnover, job absenteeism, job efficiency and so forth. In the Western Cape ten "large" factories were selected (number of Coloured workers 300 or more) and compared with 17 "small" factories (number of Coloured workers less than 50). By means of t-tests, statistical significant differences were found in respect of the following variables on which large organizations appeared more favourable: 1) more selection techniques are used; 2) selection programmes are more effective; 3) more training techniques are used; 4) training programmes are more effective; 5) workers are more satisfied; 6) the average job adjustment for workers are higher, and 7) workers are more satisfied with their salaries or wages. However, no significant differences were found in respect of labour turnover, absenteeism and job needs.
\end{abstract}

Die grootte-dimensie van organisasies is al in 'n groot mate nagevors as 'n anatomiese veranderlike. Porter, Lawler en Hackman (1975) dui as moontlike rede aan dat dit sigbaar en tasbaar is, en intuïtiewelik belangrik "blyk te wees" vir sosiale wetenskaplikes en werkers. Genoemde skrywers voer egter aan dat grootte meer as enige ander anatomiese veranderlike 'n lastige kwessie raak veral wanneer gepoog word om antwoorde te vind op vrae soos: het grootte werklik 'n invloed op werknemergedrag of is dit slegs 'n soort van verskanste tipe veranderlike wat verdwyn wanneer dit deeglik ondersoek word om die "werklike" oorsaaklike veranderlikes bloot te lê?

'n Groot mate van versigtigheid moet aan die dag gelê word met die gebruik van die term "grootte" (dit wil sê grootte van die organisasie). Alhoewel dit in die meeste gevalle

\footnotetext{
Versoeke vir afskrifte moet aan die skrywer gerig word.
} 
verwys na die aantal werknemers, maak navorsers dit dikwels nie in hul bevindings duidelik of die aantal werknemers verwys na die totale organisasie, hoof-sub-eenhede, of selfs kleinersub-eenhede nie. Dit het dan tot gevolg dat dit moeilik is om interpretasies van die gevolgtrekkings betreffende die invloed, of gebrek aan invloed van grootte te interpreteer (Porter, et al., 1975).

In hierdie ondersoek is gepoog om te bepaal of organisasiegrootte 'n invloed het op: (1) aantal keuringstegnieke wat gebruik word; (2) doeltreffendheid van personeelkeuringsprogramme; (3) aantal opleidingstegnieke; (4) doeltreffendheid van opleidingsprogramme; (5) arbeidsomset; (6) werkafwesigheid; (7) werkdoeltreffendheid; (8) werkbehoeftes; (9) werktevredenheid; (10) beroepsaanpassing en (11) tevredenheid met salarisse/lone. Organisasiegrootte verwys hier na die aantal werknemers in die organisasie of tak as geheel (dit wil sê nie grootte van werkgroepe nie).

In Tabel 1 toon Porter et al., (1975) die verband aan tussen organisasiegrootte en werkers se houdings en gedrag. Drie aspekte verdien egter hier vermelding: Eerstens, meeste van die studies maak vergelykings tussen verskillende groottes van sub-eenhede van groter organisasies eerder as tussen onafhanklike organisasies. Tweedens word verwys na positiewe en negatiewe korrelasies maar geen besonderhede word oor die beduidendheid daarvan verstrek nie. Laastens, moet in gedagte gehou word dat meeste van die studies betrekking het op gewone werkers, en derhalwe is dit nie duidelik in hoe ' $n$ mate grootte ' $n$ invloed het op houdings en gedrag van toesighoudende en bestuurspersoneel nie. Met verwysing na Tabel 1 toon vorige navorsing die volgende resultate:

(1) Ten opsigte van werkteverdenheid is oor die algemeen 'n negatiewe verband gevind wat beteken dat 'n toename in organisasiegrootte gepaard gaan met 'n afname in werktevredenheid en omgekeerd (Bass \& Barrett, 1981; Mintzberg, 1979; Siegel, 1971). Gilmer (1971) waarsku egter dat werktevredenheid afhang van baie aspekte behalwe organisasiegrootte. (2) Werkafwesigheid toon oor die algemeen 'n positiewe verband met grootte (Gilmer, 1971; Litterer, 1973). (3) 'n Toename in grootte gaan gepaard met 'n toename in arbeidsomset (Mintzberg, 1979; Gilmer, 1971). (4) Teenstrydige bevindinge ten opsigte van grootte en ongelukke is soos volg: positiewe verband (Melcher, 1976), kromlynige verband (Porter et al., 1975), en negatiewe verband (Porter, et al., 1975). Die navorser is van mening dat hierdie uiteenlopende bevindinge toegeskryf kan word aan ander faktore (soos byvoorbeeld die gevaarlikheid van die tipe werk of werkomgewing) en nie soseer organisasiegrootte nie. (5) 'n Positiewe verband is gevind tussen grootte en arbeidsgeskille 
(Mintzberg, 1979; Porter et al., 1975). (6) Die verband tussen produktiwiteit en grootte lewer ook teenstrydige resultate: negatiewe verband (Gilmer, 1971; Porter et al., 1975; Siegel \& Lane, 1974), terwyl Porter et al., (1975) ook studies aanhaal van kromlynige verband, geen verband en positiewe verband.

\section{$\underline{\text { TABEL } 1}$}

\section{NAVORSING OOR VERWANTSKAP TUSSEN GROOTTE VAN ORGANISASIE- SUB-EENHEID EN WERKHOUDINGS EN WERKGEDRAG}

\begin{tabular}{|c|c|c|c|}
\hline $\begin{array}{l}\text { Houding } \\
\text { of gedrag }\end{array}$ & $\mathrm{Navorsers}$ & Tipe Sub-eenheid & Verwantskap \\
\hline \multirow{9}{*}{$\begin{array}{l}\text { Werktevre- } \\
\text { denheid }\end{array}$} & Talacchi (1960) & Fabrieke & Negatief \\
\hline & Kerr, Koppelmeier \& & Afdelings & Negatief \\
\hline & Sullivan (1951) & & \\
\hline & Indik \& Seashore (1961) & Afdelings & Negatief \\
\hline & Katzell, Barrett, \& & Afdelings & Negatief \\
\hline & Parker (1961) & & \\
\hline & Campbell (1952) & Werkgroepe & Negatief \\
\hline & Worthy (1950) & $?$ & Negatief \\
\hline & Indik \& Seashore (1961) & Motorhandelaars & $\mathrm{Nul}$ \\
\hline \multirow[t]{14}{*}{ Afwesigheid } & Revans (1958) & Gaswerke & Positief \\
\hline & Revans (1958) & Fabrieke & Positief \\
\hline & Revans (1958) & Fabrieke & Positief \\
\hline & Action Society Trust (1953) & Fabrieke & Positief \\
\hline & Baumgartel \& Sobol (1959) & Aanlegte & Positief \\
\hline & Research Council for & Aanlegte & Positief (?) \\
\hline & $\begin{array}{l}\text { Economic Security } \\
\text { (Baumgartel \& Sobol, 1959) }\end{array}$ & & \\
\hline & Hewitt \& Parfit (1953) & Afdelings & Positief \\
\hline & Indik \& Seashore (1961) & Afdelings & Positief \\
\hline & Kerr, Koppelmeier \& & Afdelings & Positief \\
\hline & Sullivan (1951) & & \\
\hline & Metzner \& Mann (1953) & $\begin{array}{l}\text { Werkgroepe } \\
\text { (bloukraag) }\end{array}$ & Positief \\
\hline & $\begin{array}{l}\text { Argyle, Gardner \& Cioffi } \\
\text { (1958) }\end{array}$ & Werkgroepe & Kromlynig \\
\hline & Metzner \& Mann (1953) & $\begin{array}{l}\text { Werkgroepe } \\
\text { (witkraag) }\end{array}$ & Nul \\
\hline
\end{tabular}




\begin{tabular}{|c|c|c|c|}
\hline $\begin{array}{l}\text { Houdings of } \\
\text { gedrag }\end{array}$ & $\mathrm{Navorsers}$ & Tipe Sub-eenheid & Verwantskap \\
\hline Arbeidsomset & $\begin{array}{l}\text { Indik \& Seashore (1961) } \\
\text { Kerr, Koppelmeier \& } \\
\text { Sullivan (1951) } \\
\text { Mandell (1956) } \\
\text { Argyle, Gardner \& Cioffi } \\
\text { (1958) }\end{array}$ & $\begin{array}{l}\text { Motorhandelaars } \\
\text { Afdelings } \\
\text { Afdelings } \\
\text { Werkgroepe }\end{array}$ & $\begin{array}{l}\text { Positief } \\
\text { Positief } \\
\text { Positief } \\
\text { Nul }\end{array}$ \\
\hline Ongelukke & $\begin{array}{l}\text { Revans (1958) } \\
\text { Revans (1958) } \\
\text { Revans (1958) } \\
\text { Revans (1958) } \\
\text { U.S. Department of } \\
\text { Labor (Revans, 1958) } \\
\text { National Safety Council } \\
\text { (Revans, 1958) }\end{array}$ & $\begin{array}{l}\text { Myne (Brittanje) } \\
\text { Fabrieke (" ) } \\
\text { Afdelings } \\
\quad \quad \quad \text { Asië) } \\
\text { Myne (V.S.A.) } \\
\text { Fabrieke (V.S.A) } \\
\text { Fabrieke (V.S.A.) }\end{array}$ & $\begin{array}{l}\text { Positief } \\
\text { Positief } \\
\text { Positief } \\
\text { Kromlynig } \\
\text { Kromlynig } \\
\text { Negatief }\end{array}$ \\
\hline $\begin{array}{l}\text { Arbeidsdis- } \\
\text { pute }\end{array}$ & $\begin{array}{l}\text { Cleland (1955) } \\
\text { Revans (1958) }\end{array}$ & $\begin{array}{l}\text { Fabrieke } \\
\text { Myne }\end{array}$ & $\begin{array}{l}\text { Positief } \\
\text { Positief }\end{array}$ \\
\hline $\begin{array}{l}\text { Produktiwi - } \\
\text { teit }\end{array}$ & $\begin{array}{l}\text { Katzell, Barrett \& } \\
\text { Parker (1961) } \\
\text { Indik \& Seashore (1961) } \\
\text { Mariott (1949) } \\
\text { Revans (1958) } \\
\text { Revans (1958) } \\
\text { Herbst (1957) } \\
\text { Indik \& Seashore (1961) } \\
\text { Argyle, Gardner \& Cioffi } \\
\text { (1958) }\end{array}$ & $\begin{array}{l}\text { Maatskappyverde- } \\
\text { lings } \\
\text { Afdelings } \\
\text { Werkgroepe } \\
\text { Myne } \\
\text { Kleinhandelaars } \\
\text { Kleinhandelaars } \\
\text { Motorhandelaars } \\
\text { Werkgroepe }\end{array}$ & $\begin{array}{l}\text { Negatief } \\
\text { Negatief } \\
\text { Negatief } \\
\text { Kromlynig } \\
\text { Kromlynig } \\
\text { Kromlynig } \\
\text { Nul } \\
\text { Positief }\end{array}$ \\
\hline
\end{tabular}

* Oorgeneem uit: Porter \& Lawler, 1975. 'n Positiewe verwantskap dui aan dat houdings of gedrag toeneem namate grootte toeneem en andersom. 'n Kromlynige verwantskap dui 'n neiging aan vir die middelslag sub-eenheid om of die hoogste of die laagste frekwensie van houdings of gedrag te openbaar.

Ander faktore wat moontlik ook verband hou met grootte is die volgende: (1) Hoe groter die organisasie hoe meer uitgebrei is die struktuur, dit wil sê hoe meer gespesialiseerd is die take, hoe meer gedifferensieerd is sy eenhede en hoe meer gevorderd is sy administratiewe komponent (Mintzberg, 1979). (2) Individue in groter groepe is meer geneig om gevoelens van inhibisie te ervaar wanneer dit kom by deelname (Siegel \& Lane, 1974). 
(3) Soos groepe groter word neig dit in 'n groter mate na burokrasie (Thomas \& Fink, 1963).

(4) Lede van groter groepe is minder geneig om inligting te gee of hulp te vra, spanning te toon en hul gevoelens te wys (Hamblin \& Miller, 1961). (5) Groter organisasies beskik waarskynlik oor groter finansiële bronne (Hall, Haas \& Johnson, 1974). (6) Mahoney, Frost, Crandall en Weitzel (1972) wys daarop dat beide eenheidsgrootte en organisasiegrootte op drie maniere 'n verskil maak: Groter eenhede en groter firmas openbaar: (a) meer buigsaamheid in personeeltake en die ontwikkeling van werknemers vir bevordering binne die firmas; (b) meer delegasie van werkverantwoordelikheid deur toesighouers en (c) meer nadruk op resultate, uitsette en prestasie eerder as prosedures.

In die lig van bogenoemde is besluit om die moontlike invloed van organisasiegrootte te ondersoek ten opsigte van die veranderlikes soos vroeër genoem. Die redes vir hierdie ondersoek is onder andere die volgende: (1) In die studies waarna verwys word is nie konsekwent met organisasiegroottes gewerk nie maar somtyds met sub-groepe binne organisasies. Dit kan lei tot teenstrydige resultate (Andrews, 1967; Cyert \& March, 1963; Evan, 1963; Grusky, 1961). In hierdie ondersoek word 'n duidelike verdeling tussen "groot" en "klein" organisasies gemaak wat in die volgende afdeling verduidelik word. (2) Alhoewel sommige veranderlikes al in 'n groot mate ondersoek is (kyk Tabel 1) is ander veranderlikes wat in hierdie studie ondersoek word, relatief onbekend. (3) Bestaande navorsing oor die grootte van organisasies is oor die algemeen nie-kontemporêr en hierdie navorsing beoog dan om huidige resultate beskikbaar te stel. In Suid-Afrika is hierdie kwessie haas onbekend. (4) Sover bekend is studies in die verband nog nie vir bruin fabriekswerkers onderneem nie.

\section{NAVORSINGSTRATEGIE}

Die data wat in hierdie navorsing gebruik word is reeds in 1981 ingesamel met die oogmerk om die invloed van die benutting al dan nie van wetenskaplike personeelkeuringstelsels op die beroepsaanpassing en produktiwiteit van bruinwerkers te ondersoek (Van der Bank, 1981). Aangesien volledige besonderhede omtrent die organisasies, proefpersone, meetmiddels (opstel en betroubaarheid en geldigheid daarvan) in hierdie ongepubliseerde doktoralestudie uiteengesit is, word in hierdie navorsing slegs kortlliks na die aspekte verwys. 


\section{Organisasies}

Op ' $\mathrm{n}$ gestratifiseerde ewekansige wyse is " $\mathrm{n}$ monster van 43 fabrieke uit 'n totaal van ongeveer 300 in die areas Bellville, Parow, Strand, Stellenbosch en die Paarl getrek. Vir die doeleindes van hierdie studie is 10 fabrieke geselekteer met die grootste aantal werkers, en 17 met die minste werkers. Hierdie aspek word in Afdeling 3.0 bespreek.

\section{Proefpersone en verspreiding van Vraelyste}

Uit elke firma is ' $n$ monster van 20 bruin werkers getrek ongeag werksvlak of geslag. In gevalle waar minder as 20 werkers in diens was, is almal by die studie ingesluit. Spesifieke vereistes is aan die werkers gestel - soos bv. hul moes kon lees. Die betrokke vraelyste tesame met koeverte is aan die werkers oorhandig, en die doel van die studie is aan hul verduidelik. Vir meer besonderhede kyk Van der Bank (1981, Afd. 9.3).

\section{Meetmiddels}

Om 'n meting te kry van die aantal keuringstegnieke en die doeltreffende gebruik daarvan is gebruik gemaak van Vraelys D, (Van der Bank, 1981 - Bylae 3) waarin organisasies besonderhede verstrek het omtrent die volgende tegnieke: werwing, die aansoekvorm, verwysings, mediese ondersoeke, sielkundige toetse en onderhoudvoering.

Besonderhede omtrent opleiding (die aantal firmas wat daarvan gebruik maak en die doeltreffendheid daarvan) is in " $n$ groot mate verkry deur bogenoemde vraelys, en verder uit samesprekings met bestuur. Dieselfde geld ook vir metings vir arbeidsomset, en werksafwesigheid. Laasgenoemde twee veranderlikes is uitgedruk in ratiovorm vir die maand September 1980.

Metings van die werkers se gemiddelde werkdoeltreffendheid is verkry deur Vraelys C (Van der Bank, 1981) wat deur toesighouers voltooi is en 15 werksaspekte op 'n vyfpuntskaal geëvalueer het.

Besonderhede oor werktevredenheid is met behulp van Vraelys A (Van der Bank, 1981) ingesamel, wat bestaan het uit 40 werksfaktore en die werker sy tevredenheid op 'n vyfpuntskaal aangetoon het. Die werker se werksbehoeftes is verkry met Vraelys B (Van der Bank, 1981) bestaande uit 20 items ten opsigte waarvan die werker die graad van belangrikheid van elke item op 'n vyfpuntskaal moes aandui. 'n Meting van beroepsaanpassing is ver- 
kry deur die som van werksdoeltreffendheid, tevredenheid en behoeftes vir elke firma te bereken. Besonderhede oor tevredenheid met salarisse/lone is verkry uit Vraelys A en die gemiddelde vir elke fabriek is bepaal.

\section{RESULTATE}

\section{VERSPREIDING VAN GROOT EN KLEIN FIRMAS}

Soos in Afdeling 2.1 genoem is 10 fabrieke geselekteer met die grootste aantal bruin werknemers en 17 fabrieke met die kleinste aantal werkers. Meer besonderhede word verstrek in Tabel 2.

Die gemiddelde aantal werkers vir die groot firmas is ongeveer 541 met 'n standaardafwyking van 230,34. Daarenteen is die gemiddelde aantal werkers vir 17 klein firmas ongeveer 26 met 'n standaardafwyking van 10,4. Met hierdie verdeling as basis word daar in die volgende afdelings probeer bepaal in hoe 'n mate groot en klein fabrieke van mekaar verskil. In die bespreking wat volg word deurgaans verwys na Tabel 3.

\section{TABEL 2}

\section{VERSPREIDING VAN GROOT EN KLEIN FIRMAS}

\begin{tabular}{|c|c|c|c|}
\hline $\begin{array}{c}\text { Aantal } \\
\text { Werkers (N) }\end{array}$ & $\begin{array}{c}\text { Aantal } \\
\text { Werkers (N) }\end{array}$ & $\bar{X}$ & $\mathrm{~S}$ \\
\hline $\mathrm{N} \geq 300$ & 10 & 541,2 & 230,34 \\
\hline $\mathrm{N}<50$ & 17 & 26,1 & 10,4 \\
\hline
\end{tabular}

\section{Aantal keuringstegnieke (VI)}

Groot fabrieke maak gemiddeld van meer keuringstegnieke gebruik as klein firmas $(4,70$ teenoor 3,53) Hierdie verskil is statisties beduidend op die $0,1 \%$-sekerheidspeil.

\section{Doeltreffendheid van keuringstegnieke (V2)}

Die maksimum telling wat aan 'n fabriek toegeken word in hierdie afdeling is 42 (Van der Bank, 1981 - Afd. 10,4). Die groot firmas se gemiddelde telling is 21,05 teenoor die 10,32 van die klein firmas wat dui op 'n betekenisvolle verskil op die $1 \%$ - sekerheidspeil. Groot firmas se keuringstegnieke is dus gemiddeld meer doeltreffend as die van klein firmas. 
TABEL 3

VERGELYKING VAN SPESIFIEKE VERANDERLIKES TUSSEN GROOT ORGANISASIES ( $\mathrm{N} \geq 300)$ EN KLEIN ORCANISASIES $(\mathrm{N}<50)$

\begin{tabular}{|c|c|c|c|c|c|c|c|c|c|c|}
\hline \multirow{2}{*}{$V E R A N D E R L I K E S$} & \multicolumn{4}{|c|}{$N>300$} & \multicolumn{4}{|c|}{$N<50$} & \multirow{2}{*}{\begin{tabular}{|c|}
$t-$ \\
waarde \\
\end{tabular}} & \multirow{2}{*}{$\begin{array}{l}\text { beduid }= \\
\text { endheid }\end{array}$} \\
\hline & $N_{1}$ & $\bar{x}$ & $\mathrm{~s}$ & $5 \bar{x}^{2}$ & $N_{1}$ & $x$ & $\mathrm{~s}$ & $S \bar{x}^{2}$ & & \\
\hline V1 - Aantal keuringstegnieke & 10 & 4,70 & 0,82 & 0,07 & 17 & 3,53 & 0,80 & 0,04 & 3,88 & $p<0,001$ \\
\hline V2 - Doeltreffendheid van keuringstegnieke & 10 & 21,05 & 8,37 & 7,02 & 17 & 10,32 & 5,67 & 1,90 & 3,59 & $p<0,01$ \\
\hline V3 - Aantal opleidingstegnieke & 10 & 3,20 & 1,55 & 0,24 & 17 & 1,05 & 0,93 & 0,05 & 2,87 & $p<0,01$ \\
\hline V4 - Doeltreffendheid van opleidingsprogram & 10 & 11,15 & 5,42 & 2,96 & 17 & 5,41 & 2,65 & 0,41 & 3,12 & $p<0,01$ \\
\hline V5 - Arbeidsomset & 10 & 3,42 & 1,69 & 0,28 & 17 & 5,03 & 9,29 & 5,06 & $-0,70$ & $p>0,05$ \\
\hline V6 - Werkafwesigheid & 10 & 2,99 & 2,72 & 0,74 & 17 & 1,33 & 1,68 & 0,17 & 1,75 & $p>0,05$ \\
\hline V7 - Werkdoeltreffendheid & 10 & 47,80 & 6,09 & 3,72 & 17 & 52,94 & 6,21 & 2,28 & 2,10 & $p<0,05$ \\
\hline V8 - Werkbehoeftes & 10 & 74,00 & 7,48 & 5,62 & 17 & 66,82 & 11,93 & 8,41 & 1,91 & $p>0,05$ \\
\hline v9 - Werktevredenheid & 10 & 127,50 & 10,29 & 10,63 & 17 & 109,94 & 13,28 & 10,37 & 3,83 & $p<0,001$ \\
\hline Vo- Beroepsaanpassing & 10 & 249,30 & 20,28 & 41,22 & 17 & 229,71 & 22,93 & 31,02 & 2,30 & $p<0,05$ \\
\hline V11- Tevredenheid met lone en salarisse & 10 & 3,07 & 0,50 & 0,03 & 17 & 2,57 & 0,54 & 0,02 & 2,27 & $p<0,05$ \\
\hline
\end{tabular}

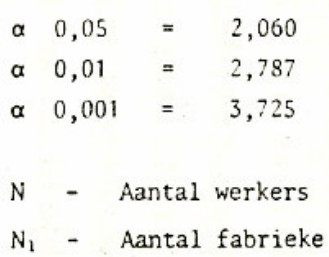

Aantal opleidingstegnieke (V3)

Groot firmas gebruik gemiddeld meer opleidingstegnieke as klein firmas $(3,20$ teenoor 1,65 - statisties beduidend op alfavlak 0,01).

\section{Doeltreffendheid van opleidingsprogramme (V4)}

Soos verwag kan word (na aanleiding van die inligting verstrek in punt 3.1.3) is die opleidingsprogramme vir groot firmas meer doeltreffend as die vir klein firmas.

\section{Arbeidsomset (V5)}

Die arbeidsomset vir klein firmas is gemiddeld hoër as dié van groot firmas (5,03 teenoor 3,42). Die verskil is egter nie statisties beduidend nie. Hierdie bevinding stem ooreen met die resultate wat verkry is deur Argyle, Gardner, en Cioffi (soos aangehaal in Porter, Lawler \& Hackman, 1975), maar verskil van die meeste ander navorsing (kyk Tabel 1). 


\section{Werkafwesigheid (V6)}

Die werkafwesigheid vir groot firmas is gemiddeld hoër as die van klein firmas maar is nie statisties betekenisvol nie. Hierdie resultaat is in 'n groot mate teenstrydig met die resultate soos vervat in Tabel 1 .

\section{Werkdoeltreffendheid (V7)}

Die gemiddelde werkdoeltreffendheid vir groot firmas is 47,80 teenoor die 52,94 vir klein firmas. Die maksimum is 75 punte. Die werksdoeltreffendheid is statisties beduidend hoër (op die $5 \%$-sekerheidspeil) vir die klein fabrieke wat in 'n geringe mate ooreenstem met die bevindinge in Tabel 1. 'n Belangrike teenstrydigheid wat hier na vore kom is dat alhoewel groot firmas meer doeltreffende keuringstegnieke en opleidingsprogramme het as klein firmas, eersgenoemde swakker of minder gemotiveerde werkers het.

\section{Werkbehoeftes (V8)}

Die teoretiese grondslag van werkbehoeftes as 'n element van beroepsaanpassing is uiteengesit in Afdeling 8.5.2 (Van der Bank, 1981). Indien in ag geneem word dat die maksimum telling 100 is, dan blyk dit dat die gemiddelde werkbehoefte vir die groot firmas 74 is teenoor die 66,82 vir klein fabrieke. Genoemde tellings kan as persentasies beskou word wat dui op relatiewe "hoë" behoeftebevredigingseise wat die werkers aan hul werk stel. Die verskil in behoeftes tussen die groot en klein organisasies is egter statisties onbeduidend.

\section{Werktevredenheid (V9)}

Die konsep werktevredenheid as 'n bestanddeel van beroepsaanpassing is bespreek in Afdeling 8.5.1 en metings van werktevredenheid is verkry met behulp van Vraelys A (Van der Bank, 1981). Die gemiddelde telling vir groot fabrieke is 127,50 en die van die klein firmas 109,94. Indien in ag geneem word dat die maksimum telling 200 is kan die twee groepe se werktevredenheid onderskeidelik gesien word as ongeveer $64 \%$ en $55 \%$. Die verskil is statisties beduidend op die $0,1 \%$-sekerheidspeil. Wat moontlik hiertoe kon bydra, is hoër salarisse/lone wat groot firmas bied, sowel as beter byvoordele. Hierdie resultate wyk egter in 'n groot mate af van die bevindinge van vorige ondersoeke soos vervat in Tabel 1. 


\section{Beroepsaanpassing (V10)}

Beroepsaanpassing wat bestaan uit die elemente werkdoeltreffendheid (V7), werkbehoeftes (V8) en werktevredenheid (V9), is die somtotaal van Vraelyste A, B en C (Van der Bank, 1981). Die gemiddelde telling van 249,30 vir groot firmas is statisties hoër (op alfavlak 0,05) as dié van die klein firmas $(229,71)$. Werkers in groot firmas se beroepsaangepastheid is dus gemiddeld beter as wat die geval in klein organisasies is.

\section{Tevredenheid met lone/salarisse (V11)}

Soos in Tabel 3 aangedui, is bruin werkers in groot fabrieke gemiddeld meer tevrede met hul salarisse/lone as bruin werkers in klein fabrieke (statisties beduidend op die $5 \%$-peil). Dit kan moontlik daaraan toegeskryf word dat eersgenoemde groep wel groter salarisse/lone ontvang.

\section{GEVOLGTREKKINGS}

Dit blyk dat groot fabrieke ten opsigte van die volgende veranderlikes "meer gunstig" vertoon as klein fabrieke: 1) meer keuringstegnieke word gebruik; 2) die doeltreffendheid van die keuringsprogram is hoër; 3) meer opleidingstegnieke word gebruik; 4) die opleidingsprogramme is meer doeltreffend; 5) werkers is meer tevrede; 6) werkers se gemiddelde beroepsaanpassing is beter, en 7) die werknemers is meer tevrede met hul salarisse of lone.

Ten opsigte van die volgende drie veranderlikes is daar geen betekenisvolle verskille tussen groot en klein fabrieke gevind nie: 1) arbeidsomset; 2) werkafwesigheid en 3) werkbehoeftes.

'n Belangrike bevinding is dat groot fabrieke se bruin werkers gemiddeld minder doeltreffend is as wat die geval is met klein fabrieke - selfs as in ag geneem word dat eersgenoemde groep oor beter keuringstegnieke en opleidingsprogramme beskik. 'n Tweede teenstrydige aspek is dat werkers in groot fabrieke meer gelukkig, maar tog swakker werkers is (in vergelyking met klein fabrieke). Dit blyk duidelik dat die grootte van 'n organisasie 'n invloed kan hê op die werker se houdings en gedrag, maar dat dit slegs een van vele veranderlikes is wat 'n rol speel. 


\title{
OPSOMMING
}

\begin{abstract}
'n Oorsig van die literatuur dui daarop dat bevindinge
onkonsekwent is wat betref die invloed van die grootte van organisasies op veranderlikes soos die doeltreffendheid van personeelkeuringstelsels, opleiding, arbeidsomset, werkafwesigheid, werkdoeltreffendheid en so meer. In Wes-Kaapland is tien "groot" fabrieke geselekteer (aantal bruin werkers 300 of meer) en vergelyk met 17 "klein" fabrieke (aantal bruin werkers minder as 50). Met behulp van t-toetse is statisties beduidende verskille gevind ten opsigte van die volgende veranderlikes waarvolgens groot organisasies meer gunstig vertoon: 1) meer keuringstegnieke word gebruik; 2) die doeltreffendheid van die keuringsprogramme is hoër; 3) meer opleidingstegnieke word gebruik; 4) opleidingsprogramme is meer doeltreffend; 5) werkers is meer tevrede; 6) werkers se gemiddelde beroepsaanpassing is beter, en 7) werkers is meer tevrede met hul salarisse of lone. Geen betekenisvolle verskille is egter gevind ten opsigte van arbeidsomset, werkafwesigheid en werkbehoeftes nie.
\end{abstract}

\section{VERWYSINGS}

Andrews, J.D. The achievement motive and advancement in two types of organizations. Journal of Personality and Social Psychology, 1967, 6, 163-168.

Bass, B.M., \& Barrett, G.V. People, work and organizations. An introduction to industrial and organizational psychology (2de uitgawe). Boston: Allyn and Bacon, 1981.

Cyert, R.M. \& March, J.G. A behavioral theory of the firm. Englewood Cliffs, N.H.: Prentice-Hall, 1963.

Evan, W. Indices of the hierarchical structure of industrial organizations. Management Science, 1963, 9, 468-477.

Gilmer, B. von H. Industrial and organizational psychology. New York: McGraw-Hill, 1971.

Hall, R.H., Haas, E.J., \& Johnson, W.J. Organizational size, complexity and formalization. American Sociological Review, 1967, 32, 903-912.

Hamblin, R.L. \& Miller, L.K. Variation interaction profiles and group size. Sociological Quarterly, 1961, 2, 105-170.

Litterer, J.A. The analysis of organizations. (2de uitgawe). New York: Wiley, 1973.

Mahoney, T.A., Frost, P., Crandall, N.F., \& Weitzel, W. The conditioning influence of organization size upon managerial practice. Organizational Behavior and Human Performance, 1972, 8, 230-241.

Melcher, A.J. Structure and process of organizations: A systems approach. Englewood Cliffs, N.J.: Prentice-Hall, 1976.

Mintzberg, H. The structuring of organizations: A synthesis of the research. Englewood Cliffs, N.J.: Prentice-Hall, 1979.

Porter, L.W., Lawler, E.E., \& Hackman, J.R. Behavior in Organizations. Tokyo: McGrawHill, 1975.

Siegel, L. Industrial Psychology (hersiene uitgawe). Homewood, Illinois: Irwin Inc., 1971.

Siegel, L. \& Lane, I.M. Psychology in industrial organizations (3de uitgawe), Homewood, Illinois.

Thomas, E.J. \& Fink, C.F. Effects of Group Size. Psychological Bulletin, 1963, 60, 371-84. 
Van der Bank, R. Die verband tussen die toepassing van wetenskaplike personeelkeuringstelsels en die beroepsaanpassing en produktiwiteit van kleurlingwerkers. Ongepubliseerde Doktorale proefskrif. Randse Afrikaanse Universiteit, 1981. 